\title{
Methods and Tools for Assessing the Vulnerability of Forests and People to Climate Change
}

An introduction

Bruno Locatelli Hety Herawati Maria Brockhaus Monica Idinoba Markku Kanninen 

Working Paper No. 43

\section{Methods and Tools for Assessing the Vulnerability of Forests and People to Climate Change}

An introduction

Bruno Locatelli

Hety Herawati

Maria Brockhaus

Monica Idinoba

Markku Kanninen

December 2008 


\section{Contact}

\section{Bruno Locatelli}

Center for International Forestry Research (CIFOR) and

Agricultural Research Center for International Development (CIRAD)

P.O. Box 0113 BOCBD

Bogor 16000

Indonesia

Tel: +62 2518622622

Fax: +62 2518622100

Email: b.locatelli@cgiar.org

Cover photo by Bruno Locatelli

\section{Acknowledgements}

The authors thank CIFOR and associated scientists who provided information about their use of methods and tools for vulnerability assessment: Benjamin Apraku Gyampoh, Angela Diaz, Heru Santoso, Houria Djoudi, Javier Saborio, Kologo Oumarou, Luis Molina, Pablo Imbach, Placide Hien, Raffaele Vignola, Stephen Lartey Tekpetey.

\section{Disclaimers}

The views expressed in this publication are those of the author(s) and not necessarily those of CIFOR.

This document has been produced with the financial assistance of the European Union (EuropeAid/ENV/200481719). The contents of this document can under no circumstances be regarded as reflecting the position of the European Union. 


\section{Abstract}

Adaptation is necessary for reducing the impacts of climate change on forests and societies. So far, forests, forest ecosystem services, and forest-dependent people or sectors have not been adequately represented in adaptation studies or policies, even though many methods and tools are available to help scientists or practitioners address questions related to vulnerability and adaptation. Methods and tools can help identify the impacts of climate change at the global, national, sectoral or local scale and bring useful results for policies on climate change. Other methods and tools aim at assessing local vulnerability for prioritising policy interventions or developing and monitoring adaptation responses.

This working paper provides an overview of methods and tools suitable for assessing the vulnerability of forests, forest ecosystem services and forest-dependent people or sectors to climate change. It provides a typology of methods and tools and gives examples, taken mostly from the experience of Center for International Forest Research (CIFOR) and Tropical Agricultural Research and Higher Education Center (CATIE) in the Tropical Forests and Climate Change Adaptation (TroFCCA) project in Central America, West Africa and Asia. The scope of the analysis is first described (section 2). Then generic methods and tools are presented (section 3), followed by methods and tools for the vulnerability of ecosystems (section 4), people (section 5), and integrated socio-ecological systems (section 6).

\section{Keywords}

Climate change, Adaptation, Vulnerability, Forest, Forest Communities, Ecosystem Services, Tools, Methods, Models. 


\section{Table of contents}

Abstract

1 Introduction

2 Scope of the Paper $\quad 6$

3 Generic Methods and Tools 9

3.1 For Analysing Vulnerability Interactively with Stakeholders 9

3.2 For Building Empirical Models from Observations 10

$\begin{array}{lll}3.3 & \text { For Various Purposes } & 10\end{array}$

4 Methods and Tools for Assessing the Vulnerability of Forests and Forest Ecosystem Services 13

4.1 Models of Partial Ecosystem Processes 13

4.2 Simple Ecosystem Models 14

4.3 Integrated Ecosystem Models $\quad 15$

5 Methods and Tools for Assessing the Vulnerability of Forest-Dependent People or Sectors 16

5.1 For Analysing Stakeholder Behaviours and Perceptions 16

5.2 For Analysing Institutions and Stakeholder Interactions 16

$\begin{array}{lll}5.3 \text { For Simulating Vulnerability } & 17\end{array}$

6 Integrative Methods and Tools $\quad 18$

7 Conclusion $\quad 19$

$\begin{array}{lr}\text { References } & 20\end{array}$ 


\section{Introduction}

A daptation is necessary for reducing the impacts of climate change on ecosystems and societies. Various pertinent questions arise when planning and implementing adaptation in any system: What will be the impacts of climate change? To what extent is the system vulnerable? Who is vulnerable? What coping strategies exist? How can adaptation decrease impacts? What can we do to adapt? What institutional support is available to enhance adaptation? How to develop adaptation policies? (UNFCCC 2004). Many methods and tools are available to help scientists or practitioners address these questions.

Methods and tools can help identify the impacts of climate change at the global scale and bring useful results for the international policies on climate change. They can also help assess the impacts at sectoral, local or national scale, for informing decision makers, raising awareness, and identifying key issues (UNFCCC 2004). In addition to these impact assessments, generally called top-down or scenario-driven, other applications of available methods and tools are bottomup or vulnerability-driven. They aim at assessing local vulnerability for prioritising policy interventions or developing and monitoring adaptation responses.

So far, forests, forest ecosystem services, and forestdependent people or sectors have not been adequately represented in adaptation studies or policies. In the National Communications of Parties of the United Nations Framework Convention on Climate Change (UNFCCC), a serious limitation in the assessment of vulnerability and adaptation comes from the unsuitability of methods and tools (UNFCCC 2005a).

This working paper provides an overview of methods and tools suitable for assessing the vulnerability of forests, forest ecosystem services and forest-dependent people or sectors to climate change. It provides a typology of methods and tools and gives examples, taken mostly from the experience of Center for International Forest Research (CIFOR) and Tropical Agricultural Research and Higher Education Center (CATIE) in the Tropical Forests and Climate Change Adaptation (TroFCCA) project in Central America, West Africa and Asia. It is a first step towards a more thorough analysis of tools and methods, including those suitable for adaptation planning and assessment.

In this paper, the scope of the analysis is first described (section 2). Then generic methods and tools are presented (section 3), followed by methods and tools for the vulnerability of ecosystems (section 4), people (section 5), and integrated socio-ecological systems (section 6). 


\section{Scope of the Paper}

Focus on methods and tools. This paper focuses on methods and tools rather than methodologies or approaches. A method is a set of steps or tasks and can be implemented through using a number of tools, i.e. a means or instrument used for accomplishing a specific task (UNFCCC 2005b). A methodology or an approach is a complete framework for guiding the assessment of vulnerability and adaptation (UNFCCC 2005a). It is composed of different methods and tools. The most commonly used frameworks are the Intergovernmental Panel on Climate Change (IPCC) technical guidelines (Carter et al. 1994), the National Adaptation Programmes of Action (NAPAs) guidelines (UNFCCC, 2002), and the Adaptation Policy Framework (Lim and Spanger-Siegfried 2004).

Focus on vulnerability. Designing, implementing and evaluating adaptation policies or projects require identifying the way in which ecosystems and societies are vulnerable to climate variability, climate change and other drivers of change (Downing and Patwardhan 2004). This paper focuses on the methods and tools available for vulnerability assessment in the specific case of forests and forest-dependent people or sectors.

In addition to vulnerability assessment, methods and tools are used for two other purposes: building scenarios and supporting decisions on adaptation (UNFCCC 2004). For building scenarios, methods and tools are described in the chapter 3.1.3 of the Compendium on Methods and Tools (UNFCCC 2005b). For supporting decisions on adaptation, methods and tools are given in chapter 5.3 of the UNEP handbook (Feenstra et al. 1998) or in chapter 3.2 of the Compendium (UNFCCC 2005b). Examples include: forecasting by analogy, screening, tool for environmental assessment and management, adaptation decision matrix, benefit-cost analysis, cost-effectiveness analysis, and implementation analysis. This paper does not present them but focuses on components of vulnerability.

According to IPCC (McCarthy et al. 2001), the three main components of vulnerability are exposure, sensitivity and adaptive capacity (see figure 1 for definitions). Exposure is external to the system, while sensitivity and adaptive capacity are internal. As an example, the three factors E, $S$ and AC explaining vulnerability of forest growth to temperature changes could be, respectively, the increase in temperature, the sensitivity of tree dynamics to temperature, and the changes of ecosystem composition following changes in tree dynamics.

\section{Figure 1: The components of vulnerability (definitions are from McCarthy et al. 2001). The signs under the arrows mean that high exposure, high sensitivity and low adaptive capacity induce high vulnerability.}

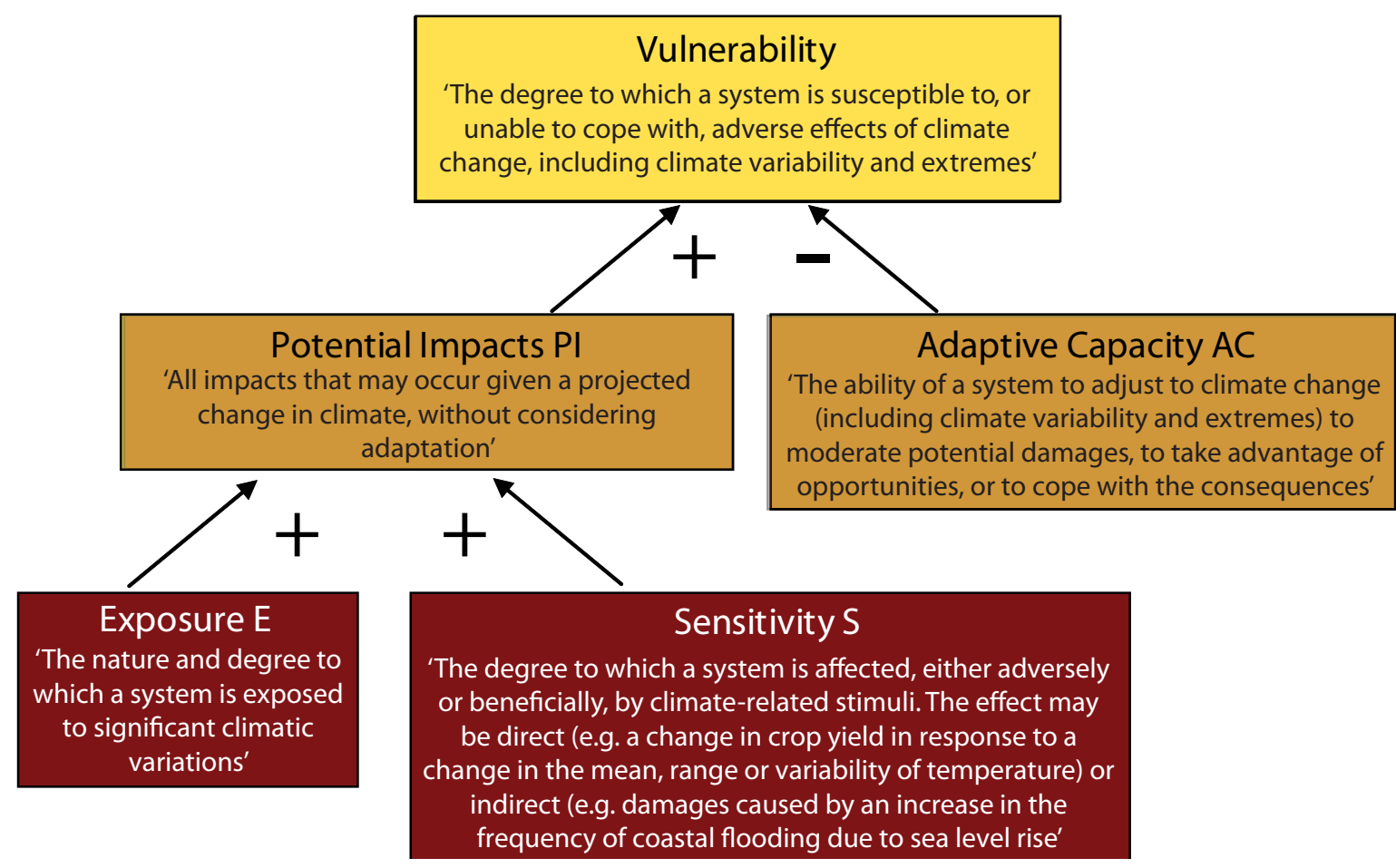


This paper focuses on methods and tools for assessing sensitivity and adaptive capacity, rather than exposure. Methods and tools for assessing exposure to climate variability, climate change and other market, social or policy pressures have been presented elsewhere. The Group on Scenarios for Climate Impact Assessment of the IPCC has produced guidelines for selecting and applying climatic or socio-economic scenarios in climate change assessment (Carter et al. 1999). Tools are available for downscaling climate scenarios to a local scale, with statistical methods such as the Statistical Downscaling Model (SDSM) (Wilby et al. 2002) or with regional climate models such as "Providing Regional Climates for Impacts Studies" (PRECIS) (Jones et al. 2004; see examples in Box 1). When a vulnerability assessment requires fine temporal climate data, tools can be used for generating daily sequences of weather variables, for instance SDSM. Other tools are described in chapter 3.1.2 of the Compendium (UNFCCC 2005b). However, as most tools for creating climate change scenarios require high levels of expertise, practitioners and scientists in the field of forestry generally use existing climate change scenarios as an input for vulnerability assessment.

Focus on local to national scales. This paper focuses on methods and tools that provide useful results for adaptation at local and national scales.

\section{Box 1: Tools used in TroFCCA for climate change scenarios}

The Model for Assessment of Greenhouse-Gas Induced Climate Change, A Regional Climate Scenario Generator (MAGICC/SCENGEN) is an user-friendly algorithm package that downscales and produces projections of regional climate change at $2.5^{\circ}$ resolution. MAGICC predicts global mean temperature and sea level rise with different emissions scenarios and SCENGEN downscales results to regional scales. More information on MAGICC/SCENGEN may be found at http:// www.cgd.ucar.edu/cas/wigley/magicc.

PRECIS is a regional climate model based on the Hadley Centre's regional climate modelling system. It can be set up over any region and run on a personal computer with a simple user interface. It can provide hourly climate variables at approximately $50 \mathrm{~km}$ resolution. PRECIS was used in TroFCCA Indonesia and West Africa. More information on PRECIS may be found at http:// precis.metoffice.com.
Many scientific works have been dealing with global assessment of impacts and vulnerability, with a low spatial resolution that impedes downscaling the findings to national or local scales. For instance, some small countries with diverse ecological and socio-economic contexts are represented by only one pixel in global assessments. However, this paper mentions the methods and tools that can be applied with a higher resolution.

At local and national scales, the application of tools and methods allows interaction with stakeholders, a key issue in assessing vulnerability and planning adaptation. Different levels of interaction are possible with the methods and tools, from a total interaction (with experiments or participatory approaches) to an absence of interaction (with abstract models of ecosystems). An intermediate level of interaction is possible with interactive models in which abstract models are presented to stakeholders who provide feedback.

\section{Focus on methods and tools easily applicable.}

This paper focuses on methods and tools that can be applied by practitioners and managers in the field of adaptation and ecosystem management. The tools and methods generally used for vulnerability assessment present different levels of complexity, from rather simple tools and methods (e.g. using expert judgement or comparing with similar cases) to complex ones (e.g. simulation of integrated socio-ecological systems or dynamic vegetation modelling). This paper gives emphasis on easily applicable methods and tools.

Focus on coupled socio-ecological systems. This report focuses on coupled socio-ecological systems, defined as integrated and complex systems in which ecosystems and society interact. As the provision of ecosystem services influences the vulnerability of society and as society affects positively or negatively the vulnerability of ecosystems, adaptation policies should aim at reducing the vulnerabilities of both ecological and social systems at the same time. Vulnerability assessment should consider the links between these two systems (see figure 2).

Few methods and tools deal with the vulnerability of coupled socio-ecological system. Some are specific to forest ecosystems, whereas others deal with social systems. An ecosystem model can provide results about the vulnerability of ecosystem services to climate change and these results can be brought into the vulnerability assessment of a social system to the loss of ecosystem services. For this reason, we will present methods and tools for forest ecosystems (section 4), social systems depending on forest ecosystem services (section 5), and coupled socio-ecological systems (section 6). 
Figure 2: Representation of a coupled socio-ecological system

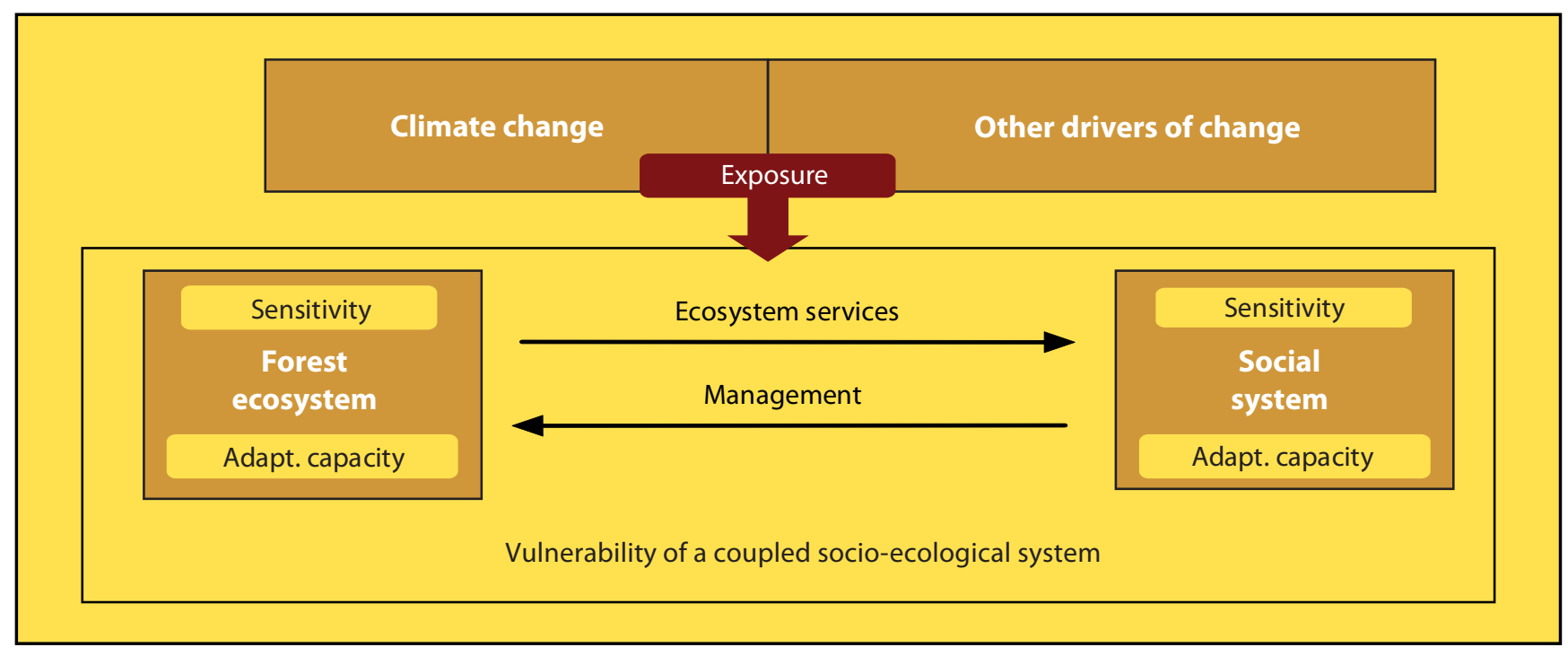




\section{Generic Methods and Tools}

Some generic methods and tools can be applied to ecosystems, social systems, or coupled socio-ecological system.

\subsection{For Analysing Vulnerability Interactively with Stakeholders}

In opposition to advanced simulation models of impacts or vulnerability that are not designed to be used by policymakers or stakeholders, methods and tools exist for involving stakeholders (including policymakers) in an assessment process. For instance, cognitive mapping and causal loop diagrams allow building formal models, either qualitative or quantitative (Giupponi et al. 2008).

We describe below two generic methods and tools for vulnerability assessment involving stakeholders and experts. Other methods are described in Downing and Ziervogel (2004), such as brainstorming or checklists. Many generic methods and tools developed and applied by social sciences can be used for vulnerability assessment (e.g. case studies, in-depth interviews, gender analysis, Venn diagram, resource mapping, community timeline, discourse analysis, close dialogue, focus groups). Many methods and tools are available at specialised websites ${ }^{1}$.

Cognitive mapping (or concept mapping or mental model) is a structured process that enables participants to produce a map of the concepts or ideas behind a topic of discussion and to describe how these ideas are interrelated. As do other methods of model-structuring (see Bana e Costa and Beinat 2005), it helps stakeholders and experts to define problems and structure their mental model. For a vulnerability assessment, cognitive mapping can start with a brainstorming about the different elements related to vulnerability, e.g drought, flooding, pests, market price fluctuation, agricultural crop yield, water scarcity, health, or infrastructure. In a second step, these elements can be clustered into groups (for example, exposure, sensitivity, and adaptive capacity; or initiating events, intermediate events, outcome, and consequences). Participants can write the elements on cards and group them on a flipchart. A third step aims at representing causal links between the elements, for instance with arrows in the flipchart. A last step consists of explaining these links.

1 For example, websites on system analysis (e.g. http://www. netsymod.eu for problem analysis and creative system modelling, Giupponi et al. 2006) or community-based adaptation (e.g. http:// www.proventionconsortium.org).

\section{Box 2: Methods and tools used in TroFCCA: Cognitive mapping}

Cognitive mapping was used in Central America for studying local stakeholders and policymakers' perceptions of the impacts of climate change on soil erosion and the role of land management in reducing the impacts (Vignola and Calvo 2008). The method was inspired by Granger Morgan, Fischhoff et al. (2001).

Cognitive mapping can also be used for simulation models as shown by van Kouwen et al. (2008). Ozesmi and Ozesmi (2004) applied a cognitive mapping approach for analysing conflicting views of stakeholders and used the results for simulating the effect of different policies. Stakeholder-oriented cognitive mapping and science-oriented simulation models can be linked, for instance when stakeholders build a cognitive map that feeds the model, which in turn informs stakeholders about results, incoherencies or gaps in data. Guidelines for and examples of cognitive mapping include Trochim (1989), Ackermann et al. (1992), Kane and Trochim (2006) and Borne (2007).

Expert judgement is a method for eliciting informed opinions from experts of a specific topic. An expert is defined as 'anyone especially knowledgeable in the field and at the level of detail being elicited' (Meyer and Booker 1991). It is a useful method when resources are lacking for conducting an in-depth analysis of scientific literature, collecting data or modelling. It is easy to implement but, due to the subjective nature of the collected information, special care must be given to the selection of experts, especially for controversial issues.

For example, elicitation of expert judgements have been applied to the case of climate change impacts on forest ecosystems at a global scale (Granger Morgan, Pitelka et al. 2001). This method can also be used for national or local issues, for example Brown and Aspinall (2004) used it for quantifying erosion rates in dams in the UK. It can also involve local stakeholders whose knowledge of the local context makes them experts for local vulnerability assessment. Guidelines for elicitation of expert judgements are available (e.g. Meyer and Booker 1991; Cooke and Goossens 1999), as well as software, such as Excalibur (Delft University of Technology 2007). 


\section{Box 3: Methods and tools used in TroFCCA: Expert judgement}

Expert judgement has been used in West Africa to identify extinct forest species and indicators for vulnerability and in Central America for eliciting information about the climatic and soil requirements of some selected species of forest plantation. The objective was to study the potential impacts of climate change on the distribution of forest plantations.

\subsection{For Building Empirical Models from Observations}

When observations are available about a phenomenon (e.g. forest fires) and possible explanatory variables (e.g. climate or human activities), empirical models can be built. These models aim at establishing a relationship between an observed impact and explanatory variables and can be used for testing the effects of changes (e.g. climate change or adaptation practices) on the phenomenon. Building models can be done with simple statistical approaches (e.g. linear models) or more elaborated methods, such as meta-analysis and data mining.

Meta-analysis is a statistical technique for combining the quantitative findings of different studies. Compared with narrative reviews of literature, metaanalysis has the advantage of producing quantitative results about impacts and uncertainties (Arnqvist and Wooster 1995). In an impact or vulnerability assessment, meta-analysis can be used for example for summarising the results of different studies of the impacts of climate change on ecosystems or human health. For example, meta-analysis has been applied to studying the effect of global warming on biodiversity (Root et al. 2003; Parmesan 2006) and soils (Rustad et al. 2001), the effects of elevated $\mathrm{CO}_{2}$ on plants (Curtis and Wang 1998), the effect of afforestation on water infiltration (Ilstedt et al. 2007), the effects of climate change on human health (Martens 1998), the drivers of food insecurity in Africa (Misselhorn 2005) or the links between risk perception and maladaptation (Milne et al. 2000).

\section{Box 4: Methods and tools used in TroFCCA: Meta-analysis}

Meta-analysis was used for studying the hydrological services delivered by forest ecosystems. The results of studies comparing watersheds under forests and non-forest land uses were synthesised. More information may be found in Locatelli and Vignola (2009).
Procedures for meta-analysis are described in many books and articles (e.g. Cooper and Hedges 1994; Osenberg et al. 1999; Gurevitch et al. 2001). Software is also available (for a review see Egger et al. 1998 or Meta-Analysis Unit 2008).

Data mining consists of sorting through large datasets and picking out relevant information. Data mining is a more powerful tool than classical statistics for searching patterns in voluminous data (Witten and Frank 2005). It can reveal complex relationships between a dependent variable and explanatory variables, e.g. relationships with nonlinearity, thresholds, and complex interactions between explanatory variables. Data mining can be used for knowledge discovery (i.e. by producing an explicit model, such as a classification tree, that can be understood by the user) or prediction (i.e. producing an explicit model or a black box used for predicting future events). Data mining is closely related to machine learning, a set of computational techniques for knowledge discovery (Recknagel 2001).

Data mining methods include classification trees, classification rules and artificial neural networks. Examples of applications include modelling forest fire (McKenzie et al. 2000; Javier Lozano et al. 2008), forecasting drought (Mishra and Desai 2006), modelling deforestation (Mas et al. 2004), modelling rainfall-runoff relationships (Dawson et al. 2006), or modelling the distribution of vegetation in future climate (Hilbert and Ostendorf 2001).

Several guidebooks are available (e.g. Witten and Frank 2005). User-friendly and open-source software makes data mining accessible to non-experts, for example Weka (Witten and Frank 2005; University of Waikato 2008).

\section{Box 5: Methods and tools used in TroFCCA: Data mining}

Data mining was used in Central America to study the relationships among forest fires and socioeconomic, biophysical and climatic variables. The objective was to study the future of forest fires under climatic and socio-economic scenarios. Data mining was applied with sets of regression trees. Find more information in Locatelli, Imbach et al. (2008).

\subsection{For Various Purposes}

Some generic methods and tools can be applied for various purposes during a vulnerability assessment, including analysing vulnerability interactively with stakeholders or building empirical models from observations. Three examples are given below: indicators, fuzzy systems and uncertainty analysis. 
Indicators. An indicator is 'something that provides a clue to a matter of larger significance or makes perceptible a trend or phenomenon that is not immediately detectable' (Hammond et al. 1995). Indicators can be used for describing the different components of vulnerability of an ecosystem, a social system or a coupled socio-ecological system. They can also be used for mapping vulnerability.

Several authors have proposed indicators of sensitivity and adaptive capacity to climate change at a national scale. Those using an inductive datadriven approach define a set of indicators and select the indicators that are the most correlated with proxies of vulnerability (e.g. using data on past disasters) or that are perceived by experts to be best indicators of vulnerability (e.g. Moss et al. 2001). For instance, Brooks et al. (2005) build a wide array of potential national-scale vulnerability indicators related to economy, health and nutrition, education, infrastructure, governance, geography and demography, agriculture, ecology and technology. They select 11 indicators that have a strong correlation with mortality from climate-related disasters.

Conversely, theory-driven studies start from assumptions about the link between vulnerability and various environmental and development factors (e.g. Cutter et al. 2003, at the scale of US counties). Adger and Vincent (2005) developed the social vulnerability index (SVI), an aggregate index of human sensitivity and adaptive capacity to climate change-induced changes in water availability. The SVI is composed of five composite subindices: economic wellbeing and stability, demographic structure, institutional stability and strength of public infrastructure, global interconnectivity and dependence on natural resources (Vincent 2004).

Adequate vulnerability indicators should summarise and measure relevant information and make vulnerability visible (Downing and Patwardhan 2004). For indicators being a way of meeting adaptation or sustainability goals, they should also be developed with active participation of local stakeholders with in-depth background understanding of the topic and the area of study (Reed et al. 2008). Criteria and procedures for selecting indicators are described in detail by Niemeijer and de Groot (2008). Several technical issues should be considered when developing and using indicators, in particular sensitivity, data reliability, collinearity and coverage of the various dimensions of vulnerability (Downing and Patwardhan 2004).

Another technical issue is related to normalisation: before being aggregated, indicator values are generally transformed into normalised indices (for instance indices between 0 and 1 or indices with a mean of 0 and a standard deviation of 1). Different methods exist for creating aggregate indices, e.g. averages or weighted averages (Malczewski 1999). Indicators can also be presented without mathematical aggregation in a vulnerability profile (Downing et al. 2001).

\section{Box 6: Methods and tools used in TroFCCA: Indicators}

Indicators of vulnerability have been developed in West Africa in a participatory way. The various dimensions of the vulnerability of social ecological systems was conceptualised by stakeholders and described with indicators (Idinoba et al. 2008). Other experiences with indicators include vulnerability of peat lands in Asia (Murdiyarso et al. 2008) and vulnerability of farmers in Central America (Benegas et al. 2009).

Fuzzy systems. Fuzzy uncertainty relates to events that have no well-defined meaning, e.g. a sustainable use of a resource, a democratic country or a vulnerable group. It describes the degree of possibility (or truth, membership, plausibility) and is different from probabilistic uncertainty (probability of occurrence of an event, based on true-or-false statements) (Cox 1994). Fuzzy systems represent a useful approach to vulnerability, as many components of vulnerability are not well-defined.

Fuzzy theory enables researchers to deal with polymorphous and ambiguous concepts for which a straightforward quantification is impossible, to mathematically handle the reasoning for these concepts and to produce concrete unambiguous answers (Phillis and Andriantiatsaholiniaina 2001). The core of the fuzzy theory is the concept of membership function. A fuzzy set in $\mathrm{X}$ is characterised by a membership function $\mathrm{f}$ that associates each point $\mathrm{x}$ in $\mathrm{X}$ with a real number in the interval $[0,1]$, representing the grade of membership of $x$ in the fuzzy set (Zadeh 1965).

Fuzzy systems enable handling linguistic variables in models of fuzzy reasoning. For instance, fuzzy functions can be defined for characterising the set of 'poor communities' and the set of 'areas critically exposed to climate change'. Then fuzzy propositions can be defined (e.g. 'IF community is poor AND area is critically exposed to climate change THEN vulnerability is high'). A series of mathematical procedures exist for working mathematically with these propositions and producing values of vulnerability (Cox 1994).

Fuzzy system theory has been used in many research and operational areas, for example, sustainability assessment (Cornelissen et al. 2001), environmental impact evaluation (Enea and Salemi 2001) or natural resource management (Bender and Simonovic 2000). The application of fuzzy systems is not highly demanding in terms of computation but can be challenging for those unfamiliar with mathematics. Tools are available, especially for Matlab ${ }^{\mathrm{TM}}$, but they also require certain ability with mathematics. 


\section{Box 7: Methods and tools used in TroFCCA: Fuzzy} systems

Fuzzy systems were used in Central America for various purposes: a fuzzy multi-criteria analysis of the impacts of payment for ecosystem services in Central America (Locatelli, Rojas and Salinas 2008), the determination of hotspots of ecosystem services for selected socio-economics sectors (Gonzalez et al. 2007; Leguia et al. 2007) and for studying the future of forest fires under climatic and socio-economic scenarios (Locatelli, Imbach et al. 2008).

Uncertainty analysis. A vulnerability assessment must recognise and inform about the uncertainties inherent in the assessment. These uncertainties come from the lack of understanding of the studied systems (e.g. the lack of knowledge about the behaviour of a social system facing climate change) and the lack of certainties about the external conditions (e.g. climate or socio-economic scenarios).
Many methods and tools exist for analysing uncertainties (New and Hulme 2000). The most common approach is the application of different climatic or socio-economic scenarios and the presentation of the range of outcomes. Another approach can involve applying different ecosystem models or different representations of a social system, for exploring a different sensitivity or adaptive capacity. It is also possible to combine different scenarios with different system models. In addition to the simple presentation of the range of outcomes, more formal methods can be applied, such as Monte Carlo analyses or Bayesian methods (see Katz, 1999). Zaehle et al. (2005) and van Oijen et al. (2005) describe uncertainty analyses in forest and global vegetation modelling. 


\section{Methods and Tools for Assessing the Vulnerability of Forests and Forest Ecosystem Services}

Assessing vulnerability of or impacts of climate change on forest ecosystems can be done through experiments (e.g. artificially modifying precipitation reaching an ecosystem or increasing the concentration of $\mathrm{CO}_{2}$ ). However, modelling studies are less costly and more flexible than experiments. According to Price and Flannigan (2000), 'It is hard to conceive of a meaningful impacts study that does not make some use of computer models'. We present different kinds of models used for ecosystem vulnerability assessment: models of partial ecosystem processes, simple ecosystem models and integrated ecosystem models.

\subsection{Models of Partial Ecosystem Processes}

Managed forests. Most models of managed forests link forest productivity with environmental variables, e.g. soils and vegetation. Various process-based models have been developed, such as 3-PG (Landsberg and Waring 1997; Landsberg et al. 2003). Other models are empirical and, from measurements of forest growth, calculate site indices representing the potential growth of a given forest species.

Hackett and Vanclay (1998) have developed a simple method for assessing the suitability of a site to a given tree species. The method is based on graphs representing a suitability index in function of a soil or climate factor (e.g. soil depth or average temperature). These graphs can be derived from an existing database or from expert judgements. For making a prediction

\section{Box 8: Methods and tools used in TroFCCA for forest plantation and climate change}

The impacts of climate change on forest plantations were studied in Central America, using information on soil and climatic requirements of selected species. The work identified areas that are suitable to forest plantations under the current climate and may become unsuitable in the future (Leguia 2008). about the suitability of a site or for creating suitability maps, suitability indices are calculated for each site factor and combined using Liebig's Law of the Minimum (i.e. the most limiting factor determines plant performance). Similar approaches based on site suitability are presented in Booth (1990) and Bones and Jones (1998).

Perturbations. Some models deal with specific ecosystem perturbations, such as fires, pests or diseases. Regarding pests and diseases in forest ecosystems, empirical studies use observations on past outbreaks (e.g. Hódar et al. 2003); biogeographical studies use data about the suitability of climate to pests (e.g. in Carroll et al. 2004); and epidemiological models represent the dynamics of well-studied pests in function of factors related to trees (e.g. bark temperature), climate (e.g. winter temperature) and pests (e.g. survival rate as a function of bark temperature) (see Bergot et al. 2004 for an example about an oat disease in Europe with scenarios of climate change).

Regarding forest fires, the availability of satellite data about fire spots makes easy and relevant the development of empirical data, with classical statistics (e.g. with linear regression in Sebastián-López et al. 2008 and with logistic regression in Westerling and Bryant 2006), with data mining (e.g. with classification trees in Sturtevant Cleland 2007 and with numeric trees in McKenzie et al. 2000) and with fuzzy logic (e.g. Iliadis 2005; Hessburg et al. 2007). Landscape models have also been developed for simulating the spread of fires or the dynamics of vegetation before and after fires (e.g. Schumacher et al. 2006; Syphard et al. 2007).

\section{Box 9: Methods and tools used in TroFCCA for perturbations}

Several tools were developed for studying the impacts of climate change on the outbreaks of bark beetles in Honduras: a statistical approach with linear modelling, a data mining approach based on decision trees, and a simulation approach with dynamic systems (Rivera 2007). Empirical models with decision trees were also developed for forest fires in Central America (Locatelli, Imbach et al. 2008). 


\section{Box 10: Tools used in TroFCCA for modelling soil erosion and landslides}

Program for Transient Rainfall Infiltration and Grid-Based Regional Slope-Stability Analysis (TRIGRS) was used in Indonesia for analysing rainfall infiltration and slope stability. The question underlying this analysis was how climate change could affect landslide susceptibility. Find more information at http://pubs.usgs.gov/of/2002/ ofr-02-424/.

Spatial Explicit Individual-based Forest Simulator (SExI-FS) was used in Indonesia for analysing the role of trees in reducing the risk of landslide. Find more information at http://www.worldagroforestry.org/sea/Products/ AFModels/SExI/index.htm.

Calibrated Simulation of Transported Erosion (CALSITE) was used in Costa Rica, Honduras and Nicaragua to predict soil erosion and sedimentation within catchments. The soil erosion model, based on the Universal Soil Loss Equation (USLE), is combined with sediment transport modelling in a geographical information system. Find more information at http://eprints.hrwallingford.co.uk/182/.

Specific ecosystem services. Some models deal with specific ecosystem services, such as hydrological services. Empirical or process-based hydrological models can be used for assessing the impacts of climate and land-use change (or impacts of climate change on ecosystems) on hydrological regimes (e.g. Ewen and Parkin 1996; Parkin et al. 1996; Bathurst et al. 2004). Some models are specifically addressing water quality issues and soil erosion, e.g. the revised universal soil loss equation used by Lim et al. (2005). Merritt et al. (2003) provide a review of erosion and sediment transport models. Some examples of tools for assessing erosion are presented in box 10 .

\subsection{Simple Ecosystem Models}

Bioclimatic models are widely used tools for assessing the impacts of climate change on species or ecosystems. Such models are static and link the geographical distribution of species or ecosystems to their environment (Guisan and Zimmermann 2000). The simplest bioclimatic methods applied to ecosystems are based on existing classifications using environmental characteristics to predict ecosystem distribution (see Leemans et al. 1996 for a review). Examples of classification include the Holdridge life zones (e.g. in Villers-Ruiz and Trejo-Vázquez 1997), the Budyko vegetation model (e.g. in Monserud et al. 1993), the Kira scheme (e.g. in Cha 1997), or the plant functional types of Box (1996).

Empirical models are also used for modelling the distribution of ecosystems, e.g. with tools such as BIOCLIM $^{2}$ (e.g. in Beaumont et al. 2005) or with an artificial neural network (Hilbert and van der Muyzenberg 1999). These models can be applied for studying the future distribution of ecosystems under climate change (Hilbert and Ostendorf 2001). More complex models predict ecosystem physiognomy from soil and climate data, e.g. BIOME (Prentice et al. 1992), applied at the global (Prentice et al. 1992) or national scale, e.g. in China (Weng and Zhou 2006).

2 http://fennerschool.anu.edu.au/publications/software/anuclim/ doc/bioclim.html.

\section{Box 11: Methods and tools used in TroFCCA: Bioclimatic models}

The vulnerability of protected areas to climate change was studied in Central America. The sensitivity was assessed with the displacement of Holdridge life zones under changing climate. The study identified the most sensitive protected areas (Locatelli and Imbach 2008).

Regarding the distribution of species, models can be built from observations and applied with climate change scenarios for predicting potential future distributions. Different methods can be used for modelling species distribution (see a review in Guisan and Zimmermann 2000), such as rectilinear models (Miles et al. 2004), regression tree analysis (Iverson and Prasad 2001), linear models, additive models, classification trees and artificial neural networks (Thuillier et al. 2006). Tools are available, such as FLORAMAP or DesktopGARP ${ }^{3}$.

A concern about the use of bioclimatic models for forecasting changes in distributions comes from the variability in the projections provided by different bioclimatic models. For this reason, some authors recommend to work with multiple models (Araújo and New 2006). One limit to forecasting future distributions is the lack of understanding of ecosystem processes such as migration or species interaction (Schmitz et al. 2003; del Barrio et al. 2006; Pearson 2006). Bioclimatic models are useful tools, however, for a first approximation of impacts of climate change on ecosystems and species (Pearson and Dawson 2003).

Community and landscape dynamics. Some models emphasise the interactions between species in an ecosystem and between ecosystem patches in a landscape (Goudriaan et al. 1999).

3 FLORAMAP http://www.floramap-ciat.org/, DesktopGarp http://www.nhm.ku.edu/desktopgarp/. See also links to available free software and tools that can be used in species distribution models at http://biodiversityinformatics.amnh.org/index. php?section=sdm_soft. 
At the patch level, gap models simulate dynamics of tree regeneration, growth and mortality and represent successional dynamics of forests over long periods of time (Price and Flannigan 2000). Examples of application include studying the distribution of trees under scenarios of climate change (Sykes et al. 1996) and developing forest management strategies for adaptation to climate change (Lindner 2000).

Schmitz et al. (2003) give examples of models representing the trophic interactions in ecosystems for studying the effects of climate change, for instance a dynamic system, linking climate with three trophic levels (plants, herbivores and carnivores) and illustrating the interactions among level in food webs. These interactions can determine the effects of climate change on ecosystems.

Landscape models simulate the interaction between spatially connected patches (Goudriaan et al. 1999). For example, Ostendorf et al. (2001) developed a spatially dynamic model of ecosystem shift using cellular automata. Spatial models are also developed for studying the sensitivity of landscapes to the changes in fire regimes induced by climate changes, for instance EMBYR (Gardner et al. 1996; Hargrove et al. 2000). He et al. (1999) link an ecosystem process model (LINKAGES) with a spatial landscape model (LANDIS) to study the response of forest species responses to climate change in heterogeneous landscapes.

\section{Box 12: Methods and tools used in TroFCCA: Community dynamics}

In Central America, the capacity of ecosystems to adapt through organisms migration was simulated with a cellular automata. The objective was to study the role of biological corridors in the adaptation of protected areas to climate change (Locatelli and Imbach 2008).

Biogeochemical models. Biogeochemical models can be used for studying the effects of climate change on the functioning of ecosystems, especially with regards to the fluxes of carbon, water and energy. The fluxes of carbon have received much attention because of the possible feedback that ecosystem changes may have on the atmosphere and climate change (Goudriaan et al. 1999). For example, the Terrestrial Ecosystem Model (TEM) is a process-based ecosystem model describing carbon and nitrogen dynamics of plants and soils for terrestrial ecosystems (McGuire et al. 1995). The CENTURY model is a general model of plantsoil nutrient cycling that allows simulating carbon and nutrient dynamics for grasslands, agricultural lands, forests and savannas (Parton et al. 1992; Lauenroth et al. 1993).

\subsection{Integrated Ecosystem Models}

Many models integrate different components, for example the distribution of ecosystem types and the functioning of these ecosystems in terms of biogeochemical cycles. These models are generally complex, especially the dynamic global vegetation models. They are generally applied at a global or continental scale but can also be used for studies at a more local scale.

Equilibrium models. Several models predict distribution and functioning of ecosystems under the assumption of equilibrium conditions of climate and vegetation (Peng 2000). For example, Mapped Atmosphere Plant Soil System (MAPSS) is a deterministic point model representing the relationship between growth and distribution of vegetation and site water-balance (Neilson 1995; Neilson and Marks 1995). It has been applied at global, continental and national scales (Neilson 1995; Bachelet et al. 1998). The BIOME3 model predicts ecosystem state in terms of plant types, total leaf area index and net primary production (Haxeltine and Prentice 1996). These outputs allow classifying ecosystems into biomes for comparison with vegetation maps.

\section{Box 13: Ecosystem models used in TroFCCA}

MAPSS was applied in Mesoamerica for assessing the impacts of climate change on ecosystems' hydrological functions. The model requires input about monthly climate (precipitation, temperature, humidity and wind speed) and soils. The outputs of the model include vegetation characteristics (such as leaf area index of trees, shrubs and grasses), monthly soil moisture, surface runoff and base flow. The model is executed in monthly time steps. The model is simple to understand, performs well and allows for easy modification of parameters for calibration. Find more information at http://www. fs.fed.us/pnw/corvallis/mdr/mapss/.

Dynamic models. Dynamic global vegetation models (DGVMs) are the most advanced ecosystem models for studying the impacts of climate change on ecosystems. They link dynamically vegetation structure and functioning, and simulate how climate change and natural disturbances affect ecosystem dynamics and processes (Peng 2000). Opposite to equilibrium models, they can simulate transient changes in ecosystems. Examples include IBIS (Foley et al. 1996; Foley et al. 2005), LPJ (Sitch et al. 2003), MC1 (Daly et al. 2000), and Orchidee (Krinner et al. 2005). Comparisons of six DGVMs are presented in Cramer et al. (2001). These models require a high level of expertise in ecosystem modelling. 


\section{Methods and Tools for Assessing the Vulnerability of Forest-Dependent People or Sectors}

Several methods and tools are available for studying the vulnerability of social systems to climate change, changes in the provision of ecosystem services and other threats. Many generic methods and tools can be applied to vulnerability assessment, such as the social impact methods (World Bank 1996, 2003), the tools used in Participatory Action Research (see box 14) or other participatory tools (Rietbergen-McCracken and Narayan 1996).

\section{Box 14: Participatory action research methods and tools used in TroFCCA}

Several tools related to participatory action research were applied in Mali and Burkina Faso, such as historical axes, fodder calendar, resource maps, problem tree, adaptation tree and other visualisation tools. Find more information in 'Methods for Monitoring and Evaluation' by International Fund for Agricultural Development (http://www.ifad.org/evaluation/guide/annexd/d. htm).

\subsection{For Analysing Stakeholder Behaviours and Perceptions}

Understanding the context and the rationale behind the behaviour of a stakeholder is crucial for analysing vulnerability. Many methods and tools are available for this purpose. For example, stakeholder analysis is a systematic methodology for identifying decision-makers and stakeholders and investigating stakeholder interests (Grimble 1998; World Bank 2003).

The sustainable livelihoods framework helps understanding and analysing livelihoods in a context of vulnerability (DFID,2001). People have access to several assets (human, natural, financial, social and physical), which are combined and used in livelihood strategies for meeting livelihoods objectives. The social, institutional and organisational environment influences the way people use their assets for their livelihood strategies. The sustainable livelihoods framework can be used for studying the vulnerability of people to climate change or the loss of ecosystem services, in combination with other threats. Knutsson and Ostwald (2006) show that the framework is an effective tool for vulnerability assessment in face of multiple changes. A livelihood sensitivity matrix can be developed for assessing how assets, activities and livelihood types are sensitive to different exposures (see an example in Downing and Ziergovel 2004). Tools are available for applying the livelihoods approach or studying local knowledge (see examples in box 15).

Other much more quantitative tools can also be used for vulnerability assessment, such input-output models, household production functions or economic and econometric modelling (Downing and Patwardhan 2004).

\section{Box 15: Tools used in TroFCCA for stakeholder analysis}

The Sustainable Livelihoods Framework and the Community-based Risk Screening Tool Adaptation \& Livelihoods (CRiSTAL) were used in Ghana and Honduras. CRiSTAL is a userfriendly tool developed by International Institute for Sustainable Development for understanding the links between local livelihoods and climate and planning adaptation projects. Find more information at http://www.iisd.org/security/es/ resilience/climate_phase2.asp.

The Agroecological Knowledge Toolkit (AKT5) was also used in Ghana to study the ecological knowledge of local people. AKT5 is a software developed by the University of Wales for facilitating knowledge acquisition from farmers and scientists or from written material. Find more information at http://akt.bangor.ac.uk/.

\subsection{For Analysing Institutions and Stakeholder Interactions}

Institutions, such as rules, norms or organisations, can influence the sensitivity or the adaptive capacity of actors. Some of the drivers of vulnerability can be understood only with an analysis of the interactions between actors and the institutions that govern behaviour (Downing and Ziervogel 2004). Even though some methods and tools described in the previous sections consider social and institutional contexts, other methods and tools were specifically developed for analysing interactions and dependence, including 
conflicts or synergies. For example, institutional analysis is an analytical approach for understanding institutional decision-making (World Bank 2003); social impact analysis is an analytical framework for identifying the social impacts of changes and the responses by people and institutions (World Bank 2003); Social Capital Assessment Tool is a set of tools for studying institutions, networks and norms (World Bank 2003); stakeholder thematic network is a method for analysing stakeholders and the networks in which they operate (Downing and Ziervogel 2004).

Policy network analysis can be used to understand which actors interact — and how—in a given policy arena. With a focus on adaptive capacity, this helps to understand vulnerability and to target policy interventions. Knowing the structure and content of a specific policy arena enables one to inform and actively influence the policy process itself. An example of policy network analysis is given in box 16 .

\section{Box 16: Methods and tools used in TroFCCA for policy network analysis}

Policy network analysis was conducted in West Africa, Central America and Indonesia for understanding the structure of the policy arena on forests and adaptation to climate change (the actors, their belief systems, their networks) and identifying windows of opportunity for mainstreaming adaptation. The approach includes interviews and mathematical procedures for representing networks. Tools such as the social network analysis software UCINET and the network visualisation software NetDraw are available at http://www.analytictech. com. Find more information in Wasserman and Faust (1994) and Hannemann (2001).

\subsection{For Simulating Vulnerability}

Vulnerability assessment can be assisted by simulation tools, for integrating diverse sources of information into a common framework and simulate the behaviour of a system facing changes. These tools can simulate the sensitivity and adaptive capacity of social systems and the impacts of changes on the systems.

One promising simulation approach is agent-based social simulation. This approach allows modelling the different elements of a system (e.g. individuals or institutions such as rules and norms), the interactions between elements at different scales (e.g. between individuals or between individuals and institutions) and the interactions with the environment (Bousquet and Le Page 2004). The main advantage of this modelling approach is that it simulates the behaviour of a system starting from assumptions about the behaviour of its elements, rather than imposing rules for the evolution of the system. For this reason it enables observing the emergence of system properties that were not obvious from the observation of the elements. The characteristics of agent-based simulation make it useful for representing complex adaptive systems and modelling vulnerability and adaptation (Patt and Siebenhuner 2005). Agent-based models have been increasingly combined with empirical methods, such as case studies, stylised facts, role-playing games and laboratory experiments (Janssen and Ostrom 2006). 


\section{Integrative Methods and Tools}

Some methods and tools have been developed for assessing the vulnerability of socio-ecological systems, taking into account the vulnerability of both ecosystems and people and their relationships. For example, the Advanced Terrestrial Ecosystem Analysis and Modelling (ATEAM, http://www.pik-potsdam.de/ateam) project developed a toolkit to assess where people or sectors may be vulnerable to the loss of ecosystem services as a consequence of climate and land use change. This approach highlights that the societal vulnerability to global change also results from impacts on ecosystems and the services they provide (Metzger et al. 2005; Metzger et al. 2006). The general framework is based on the IPCC definitions of vulnerability, exposure, sensitivity and adaptive capacity.
Within a spatially explicit and quantitative framework for vulnerability assessment, several ecosystem models are used for assessing the changes in the supply of different ecosystem services under scenarios of climate change in Europe. Then scenariobased changes in adaptive capacity are used to assess vulnerability of different sectors: agriculture, water management, energy and nature conservation. The vulnerability maps allow identification of the most vulnerable regions, the most vulnerable sectors in a given region and the least harmful scenarios for regions and sectors (Metzger et al. 2006). 


\section{Conclusion}

Various methods and tools are available for assessing the vulnerability of forests, forest ecosystem services and forest-dependent people or economic sectors. Generic methods and tools can be applied to diverse systems for analysing vulnerability interactively with stakeholders (e.g. cognitive mapping or expert judgement) and for building empirical models from observations (e.g. metaanalysis or data mining). Indicators, fuzzy systems, and uncertainty analysis can be applied for various purposes.

Numerous ecosystem models can be used for studying the impacts of climate change on forests. Some models are restricted to specific ecosystem processes (e.g. the productivity of managed forests, forest perturbations or specific ecosystem services). Simple bioclimatic models can represent the distribution of ecosystems and help assessing ecosystem vulnerability to climate change. Other simple ecosystem models deal with community and landscape dynamics, with an emphasis on the interactions between species or patches of ecosystems. Other simple ecosystem models work on biogeochemical cycles in ecosystems. Integrated ecosystem models, static or dynamic, consider many ecosystem processes and are generally complex.
Several methods and tools can be applied for assessing the vulnerability of forest-dependent people or sectors. Stakeholder analysis and sustainable livelihoods framework can be used for analysing stakeholder behaviours and perceptions. Institutional analysis and policy network analysis enable analysis of institutions and stakeholder interactions. Agent-based social simulation is a promising way for simulating vulnerability of social systems to climate change.

Whereas many methods and tools are available for analysing the vulnerability of ecosystems or social systems, methods are lacking for integrating them into vulnerability assessments of coupled socio-ecological systems. Even if different tools and methods can be applied separately to ecosystems and social systems, the challenge is to link them into an integrated assessment. Ecosystem tools are generally quantitative, while social methods are often qualitative. Time horizons and spatial scale differ also greatly between large-scale, long-term ecosystem modelling and local, short-term social vulnerability assessment. The challenge is to build methods that facilitate the links among the different approaches of vulnerability. 


\section{References}

Ackermann, F., Eden, C. and Cropper S. 1992 Getting started with cognitive mapping. Tutorial paper at the $7^{\text {th }}$ Young OR conference, University of Warwick, 13-16 April 1992, pp. 65-82.

Adger, W.N. and Vincent, K. 2005 Uncertainty in adaptive capacity. C. R. Geoscience 337: 399-410.

Araújo, M.B. and New, M. 2006 Ensemble forecasting of species distributions. Trends in Ecology and Evolution 22(1): 42-46.

Arnqvist, G. and Wooster, D. 1995 Meta-analysis: synthesizing research findings in ecology and evolution. Trends in Ecology and Evolution 10(6): 236-240.

Bachelet, D., Brugnach, M. and Neilson, R.P. 1998 Sensitivity of a biogeography model to soil properties. Ecological Modelling 109: 77-98.

Bana e Costa, C.A. and Beinat, E. 2005 Model-structuring in public decision-making. The London School of Economics and Political Science, Working Paper LSEOR 05/79.

Bathurst, J.C., Ewen, J., Parkin, G., O'Connell, P.E. and Copper, J.D. 2004 Validation of catchment models for predicting land-use and climate change impacts, 3: Blind validation for internal and outlet responses. Journal of hydrology 287: 74-94.

Beaumont, L.J., Hughes, L., Poulsen, M. 2005 Predicting species distributions: use of climatic parameters in BIOCLIM and its impact on predictions of species' current and future distributions. Ecological Modelling 186: 250-269.

Bender, M.J. and Simonovic, S.P. 2000 A fuzzy compromise approach to water resource systems planning under uncertainty. Fuzzy Sets and Systems 115, 35-44.

Benegas L., Jiménez F., Locatelli B., Faustino J., Campos M., 2009 A methodological proposal for the evaluation of farmer's adaptation to climate variability, mainly due to drought in watersheds in Central America. Mitigation and Adaptation Strategies for Global Change 14(2): 169-183.

Bergot, M., Cloppet, E., Pérarnaud, V., Déqué, M., Marçais, B. and Desprez-Loustau M.L. 2004 Simulation of potential range expansion of oak disease caused by Phytophthora cinnamomi under climate change. Global Change Biology 10: 1539-1552.

Booth, T.H. 1990 Mapping regions climatically suitable for particular tree species at the global scale. Forest Ecology and Management 36: 47-60.

Booth, T.H. and Jones, P.G. 1998 Identifying climatically suitable areas for growing particular trees in Latin America. Forest Ecology and Management 108: 167173.

Borne, J.C. 2007 Mitigating disaster: mapping cognitive processes in applying technology to crises. MSc thesis, Louisiana State University.

Bousquet, F. and Le Page, C. 2004 Multi-agent simulations and ecosystem management: a review. Ecological Modelling 176: 313-332.

Box, E.O. 1996 Plant functional types and climate at the global scale. Journal of Vegetation Science 7: 309-320.

Brooks, N., Adger, W.N. and Kelly, P.M. 2005 The determinants of vulnerability and adaptive capacity at the national level and the implications for adaptation. Global Environmental Change 15: 151-163.

Brown, A.J. and Aspinall, W.P. 2004 Use of expert opinion elicitation to quantify the internal erosion process in dams. Paper presented at the $13^{\text {th }}$ British Dams Society Conference, held at the University of Kent, Canterbury, 22-26 June 2004.

Carroll, A.L., Taylor, S.W., Régnière, J. and Safranyik, L. 2004 Effects of climate change on range expansion by the mountain pine beetle in British Columbia. In: Mountain Pine Beetle Symposium: Challenges and Solutions. October 30-31, 2003, Kelowna, British Columbia. Shore, T.L., Brooks, J.E. and Stone, J.E. (eds.) Natural resources Canada, Canadian Forest Service, Pacific Forestry Centre, Information Report BCX-399, Victoria, BC. 298p.

Carter, T.R., Parry, M.L., Harasawa, H. and Nishioka, S. 1994 IPCC technical guidelines for assessing climate change impacts and adaptations. IPCC Working Group 2; University College London, UK; National Institute for Environmental Studies, Japan.

Carter, T.R., Hulme, M. and Lal, M. [IPCC-TGCIA] 1999 Guidelines on the use of scenario data for climate impact and adaptation assessment. Version 1. Intergovernmental Panel on Climate Change, Task Group on Scenarios for Climate Impact Assessment. 69p.

Cha, G.S. 1997 The impacts of climate change on potential natural vegetation distribution. Journal of Forest Research 2: 147-152.

Cooke, R.M. and Goossens, L.H.J. 1999 Procedures guide for structured expert judgment. Delft University of Technology Delft, The Netherlands, Report prepared under contract No. ETNU-CT93-0104-NL for the Commission of European Communities.

Cooper, H. and Hedges, L.V. (eds.) 1994 The handbook of research synthesis. Russell Sage Foundation, New York, 573p.

Cornelissen, A.M.G., van den Berg, J., Koops, W.J., Grossman, M. and Udoa, H.M.J. 2001 Assessment of the contribution of sustainability indicators to sustainable development: a novel approach using fuzzy set theory. Agriculture, Ecosystems and Environment 86: 173-185.

Cox, E. 1994 The fuzzy systems handbook: a practitioner's guide to building, using, and maintaining fuzzy systems. Academic Press, Boston, MA.

Cramer, W. et al. 2001 Global response of terrestrial ecosystem structure and function to $\mathrm{CO}_{2}$ and climate change: results from six dynamic global vegetation models. Global Change Biology 7: 357-373.

Curtis, P.S. and Wang, X. 1998 A meta-analysis of elevated $\mathrm{CO}_{2}$ effects on woody plant mass, form, and physiology. Oecologia 113: 299-313.

Cutter, S.L., Boruff, B.J. and Shirley W.L. 2003 Social vulnerability to environmental hazards. Social Science Quarterly 84(2): 242-261.

Daly, C., Bachelet, D., Lenihan, J.M., Neilson, R.P., Parton, W. and Ojima, D. 2000 Dynamic simulation of treegrass interactions for global change studies. Ecological Applications 10: 449-469. 
Dawson, C.W., See, L.M., Abrahart, R.J. and Heppenstall, A.J. 2006. Symbiotic adaptive neuro-evolution applied to rainfall-runoff modelling in northern England. Neural Networks 19: 236-247.

del Barrio, G., Harrison, P.A., Berry, P.M., Butt, N., Sanjuan, M.E., Pearson, R.G. and Dawson, T. 2006 Integrating multiple modelling approaches to predict the potential impacts of climate change on species' distributions in contrasting regions: comparison and implications for policy. Environmental Science and Policy 9: 129-147.

Delft University of Technology 2007 EXCALIBUR (EXpert CALIBRation) Windows program. Delft, The Netherlands, http://dutiosc.twi.tudelft.nl/ $\sim$ risk/.

DFID 2001 Sustainable livelihoods guidance sheets. DFID, London. http://www.livelihoods.org/info/info_ guidancesheets.html.

Downing, T. and Patwardhan, A. (eds) 2004 Assessing vulnerability for climate adaptation. Technical Paper 3. In: Lim, B. and Spanger-Siegfried, E. (eds.) 2004 Adaptation policy frameworks for climate change: developing strategies, policies and measures, 67-89. Cambridge University Press, Cambridge, UK.

Downing, T. and Ziervogel, G. 2004 Choosing and adapting tools for vulnerability and adaptation assessment. Training materials produced for ENDA, SEI Oxford, UK.

Downing, T.E., Butterfield, R., Cohen, S., Huq, S., Moss, R., Rahman, A., Sokona, Y. and Stephen, L. 2001 Vulnerability indices: climate change impacts and adaptation. UNEP Policy Series 3, UNEP, Nairobi.

Egger, M., Sterne, J.A.C. and Davey Smith, G. 1998 Metaanalysis software. British Medical Journal 316. http:// www.bmj.com/archive/7126/7126ed9.htm.

Enea, M. and Salemi, G. 2001 Fuzzy approach to the environmental impact evaluation. Ecological Modelling 135: 131-147.

Ewen, J. and Parkin, G. 1996 Validation of catchment models for predicting land-use and climate change impacts, 1: Methods. Journal of Hydrology 175: 583-594.

Feenstra, J.F., Burton, I., Smith, J.B., and Tol, R.S.J. (eds.) 1998 Handbook on methods for climate change impact assessment and adaptation strategies. UNEP and Institute for Environmental Studies/Vrije Universiteit, Nairobi and Amsterdam.

Foley, J.A., Kucharik, C.J. and Polzin, D. 2005 Integrated biosphere simulator model (IBIS), version 2.5. Model product. Available on-line from Oak Ridge National Laboratory Distributed Active Archive Center, Oak Ridge, Tennessee, USA. doi:10.3334/ORNLDAAC/808.

Foley, J.A., Prentice, I.C., Ramankutty, N., Levis, S., Pollard, D., Sitch, S. and Haxeltine, A. 1996 An integrated biosphere model of land surface processes, terrestrial carbon balance, and vegetation dynamics. Global Biogeochemical Cycles 10(4): 603-628.

Gardner, R.H., Hargrove, W.W., Turner, M.G. and Romme, W.H. 1996 Climate change, disturbances and landscape dynamics. In: Walker, B. and Steffen, W. (eds.) Global change and terrestrial ecosystems, 149-172. IGBP Book Series No.2. Cambridge University Press, Cambridge.

Giupponi, C., Mysiak, J. and Sgobbi, A. 2008 Participatory modelling and decision support for natural resources management in climate change research. The Fondazione Eni Enrico Mattei, Note di Lavoro 13/2008, Milan, Italy.

Gonzalez, C., Locatelli, B., Imbach, P., Vignola, R., Campos, M., Pérez, C.J. and Vaast, P. 2007 Identificacion de bosques y sistemas agroforestales proveedores de servicios ecosistemicos para el sector agua potable en Nicaragua. Recursos Naturales y Ambiente (51-52): 33-39.

Goudriaan, J. et al. 1999 Use of models in global change studies. In: Walker, B., Steffen, W., Canadell, J. and Ingram, J. (eds.) The terrestrial biosphere and global change, 106-140. Cambridge University Press, Cambridge, UK.

Granger Morgan, M., Fischhoff, B., Bostrom, A. and Atman, C.J. 2001 Risk communication: a mental models approach. Cambridge University Press.

Granger Morgan, M., Pitelka, L.F. and Shevliakova, E. 2001 Elicitation of expert judgments of climate change impacts on forest ecosystems. Climatic Change 49: 279-307.

Grimble, R. 1998 Stakeholder methodologies in natural resource management: socioeconomic methodologiesbest practice guidelines. Natural Resources Institute, Chatham, UK.

Guisan, A. and Zimmermann, N.E. 2000 Predictive habitat distribution models in ecology. Ecological Modelling 135: $147-186$.

Gurevitch, J., Curtis, P.S. and Jones, M.H. 2001 Metaanalysis in ecology. Advances in Ecological Research 32: 199-247.

Hackett, C. and Vanclay, J.K. 1998 Mobilizing expert knowledge of tree growth with the PLANTGRO and INFER systems. Ecological Modelling 106: 233-246.

Hammond, A., Adriaanse, A., Rodenburg, E., Bryant, D. and Woodward, R. 1995 Environmental indicators: a systematic approach to measuring and reporting on environmental policy performance in the context of sustainable development. World Resources Institute, Washington, DC. 50p.

Hannemann, R.A. 2001 Introduction to social network methods, online textbook. http://www.faculty.ucr. edu/ hanneman/nettext/.

Hargrove, W.W., Gardner, R.H., Turner, M.G., Romme, W.H. and Despain, D.G. 2000 Simulating fire patterns in heterogeneous landscapes. Ecological Modelling 135: 243-263.

Haxeltine, A. and Prentice, I.C. 1996 BIOME3: an equilibrium terrestrial biosphere model based on ecophysiological constraints, resource availability and competition among plant functional types. Global Biogeochemical Cycles 10: 693-709.

He, H.S., Mladenoff, D.J. and Crow, T.R. 1999 Linking an ecosystem model and a landscape model to study forest species response to climate warming. Ecological Modelling 114: 213-233.

Hessburg, P.F., Reynolds, K.R., Keane, R.E., James, K.M. and Salter, R.B. 2007 Evaluating wildland fire danger and prioritizing vegetation and fuels treatments. Forest Ecology and Management 247: 1-17.

Hilbert, D.W. and Ostendorf, B. 2001 The utility of artificial neural networks for modelling the distribution of vegetation in past, present and future climates. Ecological Modelling 146: 311-327.

Hilbert, D.W. and van der Muyzenberg, J. 1999 Using an artificial neural network to characterize the relative suitability of environments for forest types in a complex tropical vegetation mosaic. Diversity and Distributions 5: 263-274.

Hódar, J.A., Castro, J. and Zamora, R. 2003 Pine processionary caterpillar Thaumetopoea pityocampa as a new threat for relict Mediterranean Scots pine forests under climatic warming. Biological Conservation 110: 123-129. 
Idinoba, M.E., Nkem, J., Kalame, F.B. and Coulibaly, Y. 2008 A framework for vulnerability assessment of nontimber forest goods for planning adaptation to climate change and variability in West Africa. In: Adaptation of forests and forest management to changing climate: a review of science, policies and practices. Book of abstracts, 135. Swedish University of Agricultural Sciences, Uppsala, Sweden.

Iliadis, L.S. 2005 A decision support system applying an integrated fuzzy model for long-term forest fire risk estimation. Environmental Modelling \& Software 20: 613-621.

Ilstedt, U., Malmer, A., Verbeeten, E. and Murdiyarso, D. 2007 The effect of afforestation on water infiltration in the tropics: a systematic review and meta-analysis. Forest Ecology and Management 251(1-2): 45-51.

Iverson, L.R. and Prasad, A.M. 2001 Potential changes in tree species richness and forest community types following climate change. Ecosystems 4: 186-199.

Janssen, M.A. and Ostrom, E. 2006 Empirically-based, agent-based modeling of social-ecological systems. Ecology and Society 25. http://www.ecologyandsociety. org/viewissue.php?sf=25.

Javier Lozano, F., Suárez-Seoane, S., Kelly, M. and Luis, E. 2008 A multi-scale approach for modeling fire occurrence probability using satellite data and classification trees: a case study in a mountainous Mediterranean region. Remote Sensing of Environment 112: 708-719.

Jones, R.G., Noguer, M., Hassell, D., Hudson, D., Wilson, S., Jenkins, G. and Mitchell, J. 2004 Generating high resolution climate change scenarios using PRECIS, report, Met Office Hadley Centre, Exeter, UK. http:// precis.metoffice.com.

Kane, M. and Trochim, W.M.K. 2006 Concept mapping for planning and evaluation. Sage Publications, London.

Katz, R.W. 1999. Techniques for estimating uncertainty in climate change scenarios and impact studies. In: Carter, T.R., Hulme, M. and Viner, D. (eds.) Representing uncertainty in climate change scenarios and impact studies proceedings of the ECLAT-2 Helsinki Workshop, Helsinki, Finland, 38-53.

Knutsson, P. and Ostwald, M. 2006 A process-oriented sustainable livelihoods approach: a tool for increased understanding of vulnerability, adaptation and resilience. Mitigation and Adaptation Strategies for Global Change. DOI 10.1007/s11027-006-4421-9.

Krinner, G., Viovy, N., de Noblet-Ducoudré, N., Ogée, J., Polcher, J., Friedlingstein, P., Ciais, P., Sitch, S. and Prentice, I.C. 2005 A dynamic global vegetation model for studies of the coupled atmosphere-biosphere system. Global Biogeochemical Cycles 19, GB1015, doi:10.1029/2003GB002199.

Landsberg, J.J. and Waring, R.H. 1997 A generalised model of forest productivity using simplified concepts of radiation-use efficiency, carbon balance and partitioning. Forest Ecology and Management 95(3): 209-228.

Landsberg, J.J., Waring, R.H. and Coops, N.C. 2003 Performance of the forest productivity model 3-PG applied to a wide range of forest types. Forest Ecology and Management 172: 199-214.

Lauenroth, W.K., Urban, D.L., Coffin, D.P., Parton, W.J., Shugart, H.H., Kirchner, T.B. and Smith, T.M. 1993 Modeling vegetation structure-ecosystem process interactions across sites and ecosystems. Ecological Modelling 67: 49-80.
Leemans, R., Cramer, W. and van Minnen, J.G. 1996 Prediction of global biome distribution using bioclimatic equilibrium models. In: Melillo, J.M. and Breymeyer, A. (eds.) Effects of global change on coniferous forests and grassland, 413-450. J. Wiley and Sons, New York.

Leguia, E.J. 2008 Zonas edafoclimáticas aptas para especies forestales bajo escenarios de cambio climático: un estudio de caso en Costa Rica. CATIE, Turrialba, Costa Rica.

Leguia, E.J., Locatelli, B., Imbach, P., Alpizar, F., Vignola, R. and Perez, C. 2007 Servicios ecosistémicos e hidroelectricidad en Nicaragua. Recursos naturales y ambiente 51-52: 40-47.

Lim, B. and Spanger-Siegfried, E. (eds.) 2004 Adaptation policy frameworks for climate change: developing strategies, policies and measures. Cambridge University Press, Cambridge, UK. 258p.

Lim, K.J., Sagong, M., Engel, B.A., Tang, Z., Choi, J. and Kim, K.S. 2005 GIS-based sediment assessment tool. Catena 64: 61-80.

Lindner, M. 2000 Developing adaptive forest management strategies to cope with climatic change. Tree Physiology 20: 299-307.

Locatelli, B. and Imbach, P. 2008 A conceptual model for studying the effects of landscape connectivity on ecosystem adaptation to climate change in Central America. In: Adaptation of forests and forest management to changing climate: a review of science, policies and practices. Book of abstracts, 186. Swedish University of Agricultural Sciences, Uppsala, Sweden.

Locatelli, B. and Vignola. V. 2009. Managing watershed services of tropical forests and plantations: can metaanalyses help? Forest Ecology and Management, in press.

Locatelli, B., Imbach, P., Molina, L.G. and Palacios, E. 2008 The future of forest fires in Central America under climate change and socio-economic scenarios. In: Adaptation of forests and forest management to changing climate: a review of science, policies and practices. Book of abstracts, 187. Swedish University of Agricultural Sciences, Uppsala, Sweden.

Locatelli, B., Rojas, V. and Salinas, Z. 2008 Impacts of payments for environmental services on local development in northern Costa Rica: a fuzzy multicriteria analysis. Forest Policy and Economics 10(5): 275-285.

Malczewski, J., 1999 GIS and Multicriteria Decision Analysis. John Wiley \& Sons, Canada.

Martens, W.J.M. 1998 Climate change, thermal stress and mortality changes. Social Science \& Medicine 46(3): 331-344.

Mas, J.F., Puig, H., Palacio, J.L. and Sosa-Lopez, A. 2004 Modelling deforestation using GIS and artificial neural networks. Environmental Modelling \& Software 19: 461-471.

McCarthy, J.J., Canziani, O.F., Leary, N.A., Dokken, D.J. and White, K.S. (eds.) 2001 Climate change 2001: impacts, adaptation and vulnerability. Cambridge University Press, Cambridge, UK.

McGuire, A.D., Melillo, J.M., Kicklighter, D.W. and Joyce, L.A. 1995 Equilibrium responses of soil carbon to climate change: empirical and process-based estimates. Journal of Biogeography 22: 785-796.

McKenzie, D., Peterson, D.L. and Agee, J.K. 2000 Fire frequency in the interior Columbia River basin: building regional models from fire history data. Ecological Applications 10(5): 1497-1516. 
Merritt, W.S., Letcher, R.A. and Jakeman, A.J. 2003 A review of erosion and sediment transport models. Environmental Modelling \& Software 18: 761-799.

Meta-analysis Unit 2008 Meta-analysis software. The Metaanalysis Unit, University of Murcia, Spain. http://www. um.es/facpsi/metaanalysis/software.php (Dec 2008).

Metzger, M.J., Leemans, R. and Schröter, D. 2005 A multidisciplinary multi-scale framework for assessing vulnerabilities to global change. International Journal of Applied Earth Observation and Geoinformation 7(4): 253-267.

Metzger, M.J., Rounsevell, M.D.A., Acosta-Michlik, L., Leemans, R. and Schröter, D. 2006 The vulnerability of ecosystem services to land use change. Agriculture, Ecosystems and Environment 114: 69-85.

Meyer, M. and Booker, J. 1991 Eliciting and analyzing expert judgement: a practical guide. Academic Press, London.

Miles, L., Grainger, A., Phillips, O., 2004 The impact of global climate change on tropical forest biodiversity in Amazonia. Global Ecology and Biogeography 13: 553-565.

Milne, S., Sheeran, P. and Orbell, S. 2000 Prediction and intervention in health-related behaviour: a meta-analytic review of protection motivation theory. Journal of Applied Social Psychology 30: 106-143.

Mishra, A.K. and Desai, V.R. 2006 Drought forecasting using feed-forward recursive neural network. Ecological Modelling 198: 127-138.

Misselhorn, A.A. 2005 What drives food insecurity in southern Africa? A meta-analysis of household economy studies. Global Environmental Change 15: 33-43.

Monserud, R.A., Tchebakova, N.M. and Leemans, R. 1993 Global vegetation change predicted by the modified Budyko model. Climatic Change 25: 59-83.

Moss, R.H., Brenkert, A.L. and Malone, E.L. 2001 Vulnerability to climate change: a quantitative approach. US Department of Energy, Oak Ridge, TN.

Murdiyarso, D., Santoso, H. and Idinoba, M. 2008 The challenges of assessing climate change vulnerability using an ecosystem approach. In: Adaptation of forests and forest management to changing climate: a review of science, policies and practices. Book of abstracts, 210. Swedish University of Agricultural Sciences, Uppsala, Sweden.

Neilson, R.J. and Marks, D. 1995 A global perspective of regional vegetation and hydrologic sensitivities from climatic change. Journal of Vegetation Science 5: 715-730.

Neilson, R.P. 1995 A model for predicting continental scale vegetation distribution and water balance. Ecological Applications 5: 362-385.

New, M. and Hulme, M. 2000. Representing uncertainty in climate change scenarios: a Monte-Carlo approach. Integrated Assessment 1: 203-213.

Niemeijer, D. and de Groot, R.S. 2008 A conceptual framework for selecting environmental indicator sets. Ecological Indicators 8: 14-25.

Osenberg, C.W., Sarnelle, O., Cooper, S.D. and Holt, R.D. 1999 Resolving ecological questions through metaanalysis: goals, metrics, and models. Ecology 80(4): 1105-1117.

Ostendorf, B., Hilbert, D.W. and Hopkins, M.S. 2001 The effect of climate change on tropical rainforest vegetation pattern. Ecological Modelling 145: 211-224.

Ozesmi, U. and Ozesmi, S.L. 2004 Ecological models based on people's knowledge: a multi-step fuzzy cognitive mapping approach. Ecological Modelling 176: 43-64.
Parkin, G., O’Donnell, G., Ewen, J., Bathurst, J.C., O'Connell, P.E. and Lavabre, J. 1996 Validation of catchment models for predicting land-use and climate change impacts, 2: Case study for a Mediterranean catchment. Journal of Hydrology 175: 595-613.

Parmesan, C. 2006 Ecological and evolutionary responses to recent climate change. Annual Review of Ecology, Evolution, and Systematics 37: 637-669.

Parton, W.J., McKeown, B., Kirchner, V. and Ojima, D.S. 1992 CENTURY users manual. Colorado State University, NREL Publication, Fort Collins, CO, USA. http://www.nrel.colostate.edu/projects/century/.

Patt, A. and Siebenhuner, B. 2005 Agent based modeling and adaptation to climate change. Vierteljahrshefte zur Wirtschaftsforschung (Quarterly Journal of Economic Research, German Institute for Economic Research) 74(2): 310-320.

Pearson, R.G. 2006 Climate change and the migration capacity of species. Trends in Ecology and Evolution 21(3): 111-113.

Pearson, R.G. and Dawson, T.P. 2003 Predicting the impacts of climate change on the distribution of species: are bioclimate envelope models useful? Global Ecology and Biogeography 12: 361-371.

Peng, C. 2000 From static biogeographical model to dynamic global vegetation model: a global perspective on modelling vegetation dynamics. Ecological Modelling 135(1): 35-54.

Phillis, Y.A. and Andriantiatsaholiniaina, L.A. 2001 Sustainability: an ill-defined concept and its assessment using fuzzy logic. Ecological Economics 37: 435-456.

Prentice, I.C., Cramer, W., Harrison, S.P., Leemans, R., Monserud, R.A. and Solomon, A.M. 1992 A global biome model based on plant physiology and dominance, soil properties and climate. Journal of Biogeography 19(2): 117-134.

Price, D.T. and Flannigan, M.D. 2000 Modelling impacts of climate change on forests and. forestry using climate scenarios. In: Cramer, W., Doherty, R., Hulme, M. and Viner, D. (eds.) Climate scenarios for agricultural and ecosystem impacts. Proceedings of the EU Concerted Action Initiative ECLAT-2 Workshop 2, Potsdam, Germany, 13-15 October 2000, Climatic Research Unit, Norwich, UK.

Recknagel, F. 2001 Applications of machine learning to ecological modelling. Ecological Modelling 146: 303-310.

Reed, M.S., Dougill, A.J. and Baker, T.R. 2008 Participatory indicator development: what can ecologists and local communities learn from each other? Ecological Applications 18(5): 1253-1269.

Rietbergen-McCracken, J. and Narayan, D. 1996 Participation and social assessment: tools and techniques. Report 17796. World Bank, Washington, DC. http:// go.worldbank.org/N7INBJAZ00.

Rivera, M. 2007 Impacto potencial del cambio climatico en eventos epidémicos del gorgojo descortezador del pino Dendroctonus frontalis en Honduras. MSc thesis, CATIE, Turrialba, Costa Rica.

Root, T.L., Price, J.T., Hall, K.R., Schneider, S.H., Rosenzweig, C. and Pounds, J.A. 2003 Fingerprints of global warming on wild animals and plants. Nature 421: 57-60.

Rustad, L.E., Campbell, J.L., Marion, G.M., Norby, R.J., Mitchell, M.J., Hartley, A.E., Cornelissen, J.H.C. and Gurevitch, J. 2001 A meta-analysis of the response of soil respiration, net nitrogen mineralization, and 
aboveground plant growth to experimental ecosystem warming. Oecologia 126: 543-562.

Schmitz, O.J., Post, E., Burns, C.E. and Johnston, K.M. 2003 Ecosystem responses to global climate change: moving beyond color mapping. BioScience 53(12): 1199-1205.

Schumacher, S., Reineking, B., Sibold, J. and Bugmann, H. 2006 Modeling the impact of climate and vegetation on fire regimes in mountain landscapes. Landscape Ecology 21(4): 539-554.

Sebastián-López, A., Salvador-Civil, R., Gonzalo-Jiménez, J. and SanMiguel-Ayanz, J. 2008 Integration of socioeconomic and environmental variables for modelling long-term fire danger in southern Europe. European Journal of Forest Research 127(2): 149-163.

Sitch, S. et al. 2003 Evaluation of ecosystem dynamics, plant geography and terrestrial carbon cycling in the LPJ dynamic global vegetation model. Global Change Biology 9, 161-185.

Sturtevant, B.R. and Cleland, D.T. 2007 Human and biophysical factors influencing modern fire disturbance in northern Wisconsin. International Journal of Wildland Fire 16: 398-413.

Sykes, M.T., Prentice, I.C. and Cramer, W. 1996. A bioclimatic model for the potential distribution of North European tree species under present and future climates. Journal of Biogeography 23: 203-233.

Syphard, A.D., Yang, J., Franklin, J., He, H.S. and Keeley, J.E. 2007 Calibrating a forest landscape model to simulate frequent fire in Mediterranean-type shrublands. Environmental Modelling \& Software 22: 1641-1653.

Thuillier, W., Lavorel, S., Sykes, M.T. and Araújo, M.B. 2006 Using niche-based modelling to assess the impact of climate change on tree functional diversity in Europe. Diversity and Distributions 12: 49-60.

Trochim, W. 1989 An introduction to concept mapping for planning and evaluation. Evaluation and Program Planning 12, 1-16.

UNFCCC 2002 Annotated guidelines for the preparation of national adaptation programmes of action. UNFCCC, Bonn, Germany.

UNFCCC 2004 Application of methods and tools for assessing impacts and vulnerability, and developing adaptation responses: background paper. FCCC/ SBSTA/2004/INF.13. Bonn, Germany. http://unfccc. int/resource/docs/2004/sbsta/inf13.pdf.

UNFCCC 2005a Sixth compilation and synthesis of initial national communications from Parties not included in Annex I to the Convention. FCCC/SBI/2005/18. Bonn, Germany. http://unfccc.int/resource/docs/2005/sbi/ eng/18.pdf.

UNFCCC 2005b Compendium on methods and tools to evaluate impacts of, and vulnerability and adaptation to, climate change. UNFCC Secretariat. 155p.

University of Waikato 2008 Weka 3: data mining software in Java. University of Waikato, New Zealand. http://www. cs.waikato.ac.nz/ $\sim \mathrm{ml} /$ weka/. van Kouwen, F., Schot, P.P. and Wassen, M.J. 2008 A framework for linking advanced simulation models with interactive cognitive maps. Environmental Modelling \& Software 23: 1133-1144.

van Oijen, M., Rougier, J. and Smith, R. 2005 Bayesian calibration of process-based forest models: bridging the gaps between models and data. Tree Physiology 25: 915927.

Vignola, R. and Calvo, G. 2008 Hydrological services for hydropower production in the context of land use and climate change: mainstreaming ecosystem management into adaptation strategies in Reventazon watershed, Costa Rica. International Seminar on Adaptation to Climate Change: the Role of Ecosystem Services, 3-5 November 2008, CATIE, Turrialba, Costa Rica.

Villers-Ruiz, L. and Trejo-Vázquez, I. 1997 Assessment of the vulnerability of forest ecosystems to climate change in Mexico. Climate Research 9: 87-93.

Vincent, K. 2004 Creating an index of social vulnerability for Africa. Working Paper 56. Tyndall Centre for Climate Change Research, University of East Anglia, Norwich, UK.

Wasserman, S. and Faust, K. 1994 Social network analysis. Cambridge University Press, Cambridge.

Weng, E.S. and Zhou, G.S. 2006 Modeling distribution changes of vegetation in China under future climate change. Environmental Modeling and Assessment 11: 45-58.

Westerling, A. and Bryant, B. 2006 Climate change and wildfire in and around California: fire modeling and loss modeling. Report CEC-500-2006-190-SF. California Climate Change Center, California Energy Commission, California Environmental Protection Agency, Sacramento.

Wilby, R.L., Dawson, C.W. and Barrow, E.M. 2002 SDSM-a decision support tool for the assessment of regional climate change impacts. Environmental and Modelling Software 17: 145-157.

Witten, I. and Frank, E. 2005 Data mining: practical machine learning tools and techniques, 2nd ed. Morgan Kaufmann, San Francisco.

World Bank 1996 Appendix 1: methods and tools. In: The World Bank participation sourcebook, 181-204. World Bank, Washington, DC. http://www.worldbank.org/ wbi/sourcebook/sbpdf.htm.

World Bank 2003 Economic and social tools for poverty and social impact analysis. In: A user's guide to poverty and social impact analysis, 47-80. World Bank, Washington, DC. http://go.worldbank.org/8921B8K420.

Zadeh, L.A. 1965 Fuzzy sets. Information and Control 8, 338-353.

Zaehle, S., Sitch, S., Smith, B. and Hatterman, F. 2005 Effects of parameter uncertainties on the modelling of terrestrial biosphere dynamics. Global Biogeochem Cycles 19: GB3020. 



\section{Center for International Forestry Research (CIFOR)}

CIFOR advances human wellbeing, environmental conservation, and equity by conducting research to inform policies and practices that affect forests in developing countries. CIFOR is one of 15 centres within the Consultative Group on International Agricultural Research (CGIAR). CIFOR's headquarters are in Bogor, Indonesia. It also has offices in Asia, Africa and South America. CIFOR works in over 30 countries worldwide and has links with researchers in 50 international, regional and national organisations.

To request a copy of this publication, please contact cifor@cgiar.org

\section{www.cifor.cgiar.org}

